\title{
APPLICATION OF THE ANALYTIC NETWORK PROCESS (ANP) TO SELECT NEW FOREIGN MARKETS TO EXPORT SOFTWARE SERVICES: STUDY OF COLOMBIAN FIRMS
}

\author{
Diana Lesmes* \\ Industrial Engineering Department \\ Universidad de los Andes \\ Bogotá, Colombia \\ E-mail: d-lesmes@uniandes.edu.co \\ Luis Buitrago \\ International Business School \\ Universidad del Rosario \\ Bogotá, Colombia \\ E-mail: luis.buitrago36@urosario.edu.co \\ Carolina Cendales \\ International Business School \\ Universidad del Rosario \\ Bogotá, Colombia \\ E-mail: cendales.sonia@ur.edu.co
}

\begin{abstract}
The selection of export markets is a complex and important decision for small and medium enterprises (SMEs) of developing countries interested in exporting for the first time. Given this issue, SMEs enroll export programs to receive consultancy for their internationalization process. One of these export programs is managed by the Colombian trade bureau, a Trade Promotion Organization (TPO). This TPO developed a market selection model that lacks a process to validate the weights selected. Therefore, the results of the TPO model are deficient in generating enough confidence to motivate the company's owners to export. On the other hand, we identified that some of the criteria used in the TPO model were related to each other, but this model assumes criteria as independent. Due to the fact that the selection of export markets is a multi-criteria decision that involves feedback, we proposed an ANP model for selecting countries to export software services for Colombian SMEs. Upon comparing the market TPO selecting model to the ANP model, we identified that the results of both models are similar in ranking the countries. However, we concluded that the proposed model is better because it has a structured methodology to assign weights that allows evaluating the consistency of the weights allocated to the selected criteria. Besides, we also preferredit because allows analyzing sensitivity to changes in the priority's weights. The categories of variables that we used in both models are: market, economy and logistics, among other.
\end{abstract}

Keywords: Analytic Network Process, Software Services, International Commerce, Selection of Markets

\footnotetext{
${ }^{*}$ Corresponding author
} 


\section{Introduction}

In this research we developed a model for selectingsuitable countries to export using the ANP. Currently, a model developed by a TPO, managed by the Colombian trade bureau, is used to rank countries to export for SMEs. But this model lacks a process to validate the weights assigned to the criteria and the alternatives. Therefore, the TPO model's results are deficient in generating enough confidence to motivate the company's owners to export. Besides, we identified that the market selecting criteria used in the TPO model were related to each other. Thus, we proposed an ANP model for selectingsuitable countries to export. This is a multi-criteria decision model that allows checking the consistency of the weights assigned to the criteria and the alternatives and that also allows taking into account the feedback relations among criteria.

We decided to develop an ANP model for only one economic sector due to the fact that in previews investigations we noticed that the criteria selected to make part of the model and its feedback relations depend on the analyzed sector (Lesmes, 2008). We focused in the software services sector because the TPO developed a special program to help SMEs of that sector to export.This program facilitated the contact with the companies and, thus, with the data gathering. We selected ten companies that make part of that program and we applied the ANP model and the TPO model for each of those.Then, the results obtained with both models were compared.

This research was guided by a panel of experts in foreign trade, and by other sources as publications and internet. These publications and the panel of experts helped us to define the actors, the criteria and the relations of influence among the criteria. We used mainly two books to define the criteria:Competitividad de la empresa exportadora española(Alonso \& Donoso, 1994) and Pymes: gestión para la competitividad;mostly,the chapter 4 of the last one, named Inteligencia de mercados para la gestión internacional de la pyme(Ferro \& al., 2004). The sources that we used from internet to find studies and statistical data related to different countries' market conditions were Proexport (www.proexport.com.co), ICEX (www.icex.es) and Prochile (www.prochile.cl).Those institutions are TPOs from Colombia, Spain and Chile, respectively.

This paper is organized as follows:in section 2, we describe the market selection theory. In section 3 we present the theory and the methodology of this research. In section 4, we show the TPO model and the ANP model proposed for ranking the countries. In section 5, we compare the results obtained with the TPO model and the ANP model. Finally, in section 6, we describe the conclusions and recommendations of the investigation.

\section{Foreign market selection theory}

A TPO managed by the Colombian trade bureau developed a special program to help SMEs to export. The program consists of seven stages, as shown in Figure 1. In the first stage, the SMEs are motivated to export. In the second stage, a review of all the requirements that the company must achieve to export is made. In the third stage the selection of export markets is made. Afterwards, the export strategy is designed. In the fifth stage, the company should start exporting. In the sixth one, the company's owners must be prepared to make a business trip. Finally, an assessment of the export process is made (Proexport, 2006).

In this research we only focused in the third stage: the selection of exports markets.In this stage, a previews research of the possible countries where the company should export is made. Afterwards, some selected criteria are used to reduce the markets of interest until the companies end up the process with five countries. To make a ranking of those countries, the TPO developed a market selection matrix, which is described in sections 3 and 6 of this paper. 


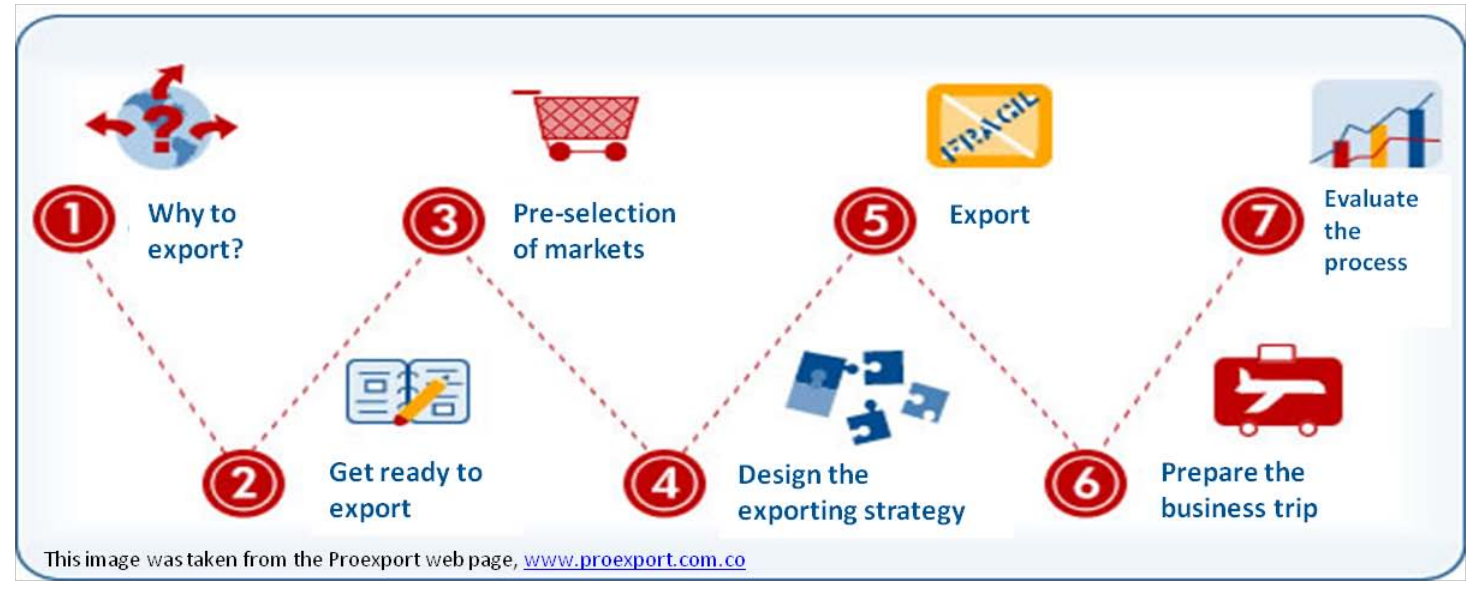

Figure 1. TPO export program

\section{Research theory and methodology}

In this section we make a general description of the TPO market selection matrix and we make an ANP theory overview.Then, we describe the methodology that we are going to follow for the development of this paper.

\subsection{TPO market selection matrix}

The matrix shown in Figure 2 was designed by a TPO named Proexport, which is the organization in charge of promoting exports, international tourism and foreign investment in Colombia. The market selection matrix makes part of the third stage of the TPO export program. As said earlier, this matrix is only used until the markets of interest are reduced to five countries. The matrix manages information about different countries and different variables, which are used to evaluate the selection of a market. The current matrix allows determining the variables that the company's owners and the consultant want to include.

\begin{tabular}{|l|l|l|l|l|l|l|}
\hline \multicolumn{1}{|l|}{ PROEXPORT } \\
\hline VarOMBIA
\end{tabular}

Figure 2. TPO market selection matrix 
The variables in the matrix depend on the product or the service that the company sells. The evaluated countries are selected previously by the company's owners; those markets are the ones that are going to be evaluated for exporting the service, in this case. The qualification is a grade that the company's owners assign to each country according to its performance with respect to the evaluated variable. This qualification depends on the company's owners criteria. The weights represent the relative importance of each variable. The weights assigned to each variable rely on the company's owners and the consultant criteria. The final result per country arises from adding the multiplication between the variable's weight and the correspondent value that takes the country's variable. The country ranking is obtained from those results.

\subsection{ANP theory overview}

The Analytic Hierarchy Process (AHP) and its extension, the ANP, are tools used in multi-criteria decision analysis. The AHP consists of one goal, some criteria and alternatives, which are arranged in a hierarchy structure where the lower level elements influence on higher level elements, as shown in Figure 3. Nevertheless, many decision problems cannot be structured in a hierarchy because they involve dependences between the alternatives, dependences of the criteria that belong to a same level, or dependence of higher level elements on lower level elements, besides the mentioned relations (Saaty T. L., 2001, pp. 83-84, 180). This concern motivated Thomas Saaty to develop the ANP, which makes possible a natural development of the problembecause it doesnot impose a structure (Saaty T. L., 2001, p. 181).As Figure 3shows, a network can be extended in all directions.

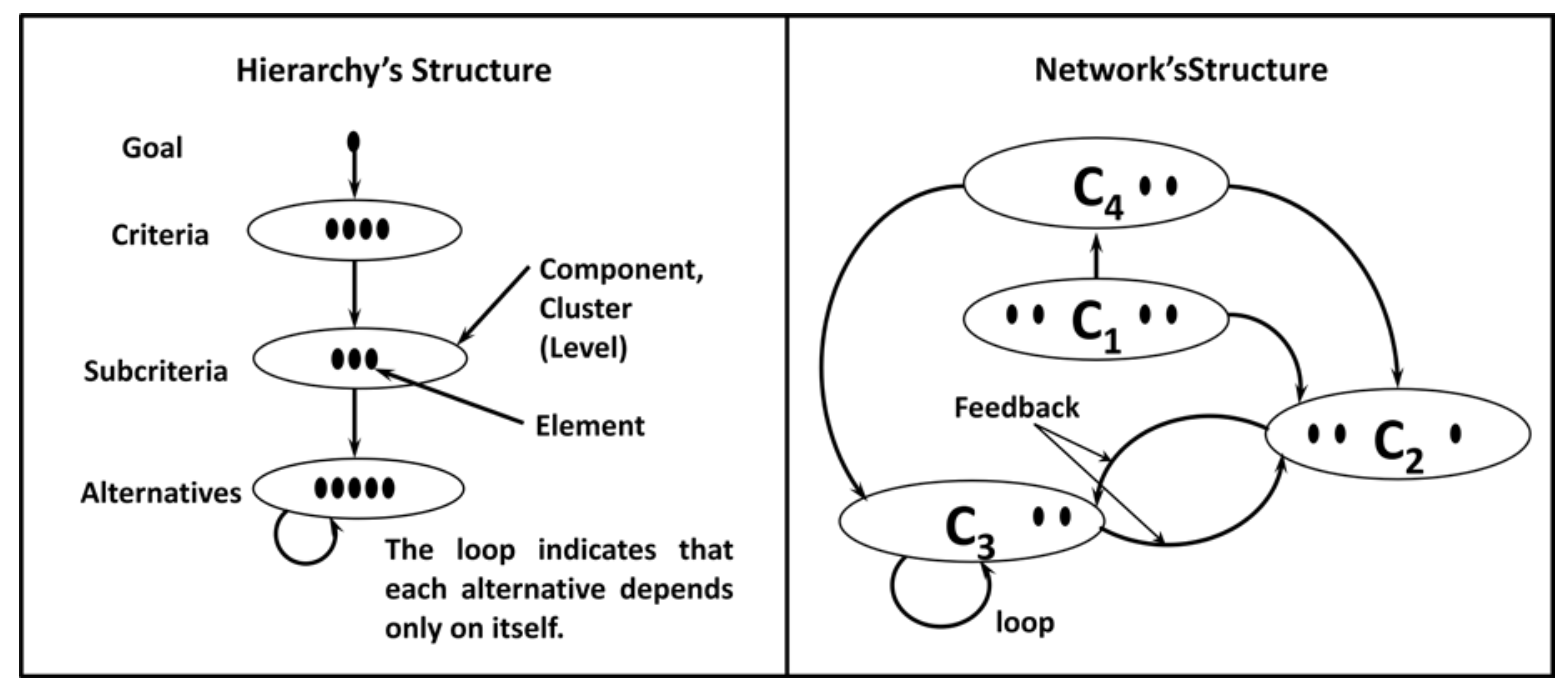

Figure 3. Hierarchy’s and network’s structures

In order to obtain the priorities to rank alternatives in a decision model, the ANP uses pairwise comparisons. A pairwise comparison matrix is form when comparing a pair or more pairs of elements with respect to a reference element, which remains unchangeable for all the comparisons. To make such comparison, Thomas Saaty developed the scale shown in Table 1, which allows measuring the strength of the judgments (Saaty T. L., 2008, p. 7).

Table 1. Saaty’s fundamental scale

\begin{tabular}{|l|l|}
\hline Intensity of importance & Definition \\
\hline 1 & Equal importance \\
\hline
\end{tabular}




\begin{tabular}{|l|l|}
\hline 3 & Moderate importance \\
\hline 5 & Strong importance \\
\hline 7 & Very strong importance \\
\hline 9 & Extreme importance \\
\hline $2,4,6,8$ & Intermediate values \\
\hline
\end{tabular}

In order to validate the judgments' consistency of the pairwise comparisons matrices, the consistency ration (C.R.)of the matrices is calculated. According to Saaty (2001, p. 57), the consistency ratio should be less or equal to 0.1 , where 0.2 is the maximum value that can be tolerated. In order to calculate the consistency ratio of matrix A, for example, it is necessary first to determine the consistency index:

$$
\text { ConsistencyIndexofMatrix } A=C . I .(A)=\frac{\lambda_{\max }-n}{n-1}
$$

Matrix theory states that a reciprocal matrix, as the case of the pairwise comparison matrix, is consistent when the maximum matrix's eigenvalue is equal to the size of a square matrix $n \times n$. In this sense, the consistency index should approach to zero. A pairwise comparison matrix is consistent if their judgments are ruled by the transitivity principal (Saaty T. L., 2005, pág. 51). Before calculating the C.R., it is necessary to estimate the averaged random consistency index (R.I.), which is obtained from random reciprocal matrix using Saaty's fundamental scale. Assuming that a random matrix does not have to be necessarily consistent, it is expected that the R.I. should be greater than the C.I. (Saaty T. L., 2001, p. 57), and therefore, the C.R. should be small. The C.R. of matrix A is defined as follows:

$$
\text { ConsistencyRatioofmatrix } A=C \cdot R \cdot(A)=\frac{C \cdot I \cdot(A)}{R \cdot I .}
$$

From the pairwise comparison matrices is obtained an eigenvector of priorities. Those priorities allow comparing the relative importance of some elements respect to the criteria or the element to which they were compared. When all the eigenvector of the decision model are calculated, these are used to form the unweighted supermatrix. Assumethat there are $\mathrm{N}$ components to construct this matrix. Also, assume that the component $\mathrm{h}$, denoted by $\mathrm{C}_{\mathrm{h}}, \mathrm{h}=1, \ldots, \mathrm{N}$, has $\mathrm{n}_{\mathrm{h}}$ elements, that are denoted by $\mathrm{e}_{\mathrm{h} 1}, \mathrm{e}_{\mathrm{h} 2}, \ldots, e_{h_{n_{k}}}$ as shown in Figure 4(Saaty T. L., 2005, pág. 51).

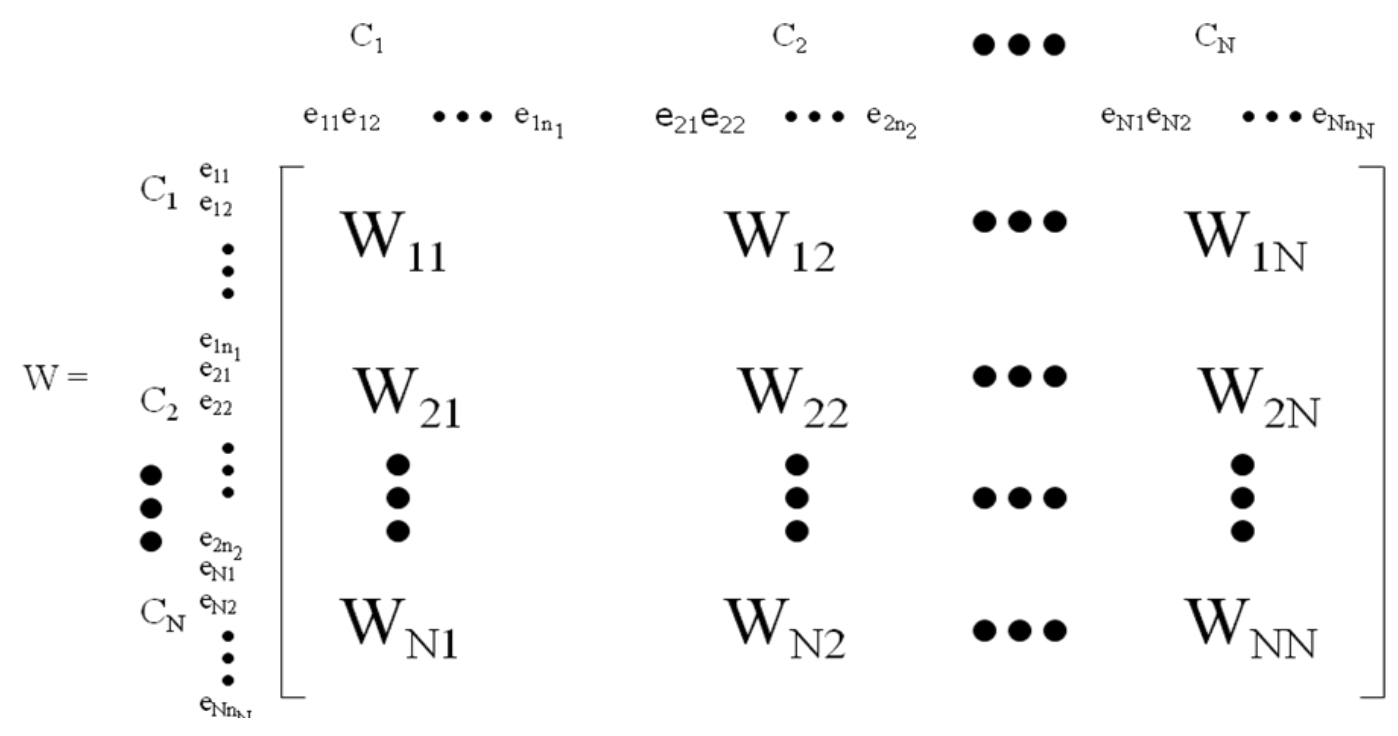

Figure 4. Supermatrix structure 
In the supermatrix, each of the eigenvector is assigned to the correspondent column. The elements in the superior row are the criteria used as reference for making the comparison. If there is no influence of the left column element with respect to the criteria in the superior row, the correspondent value in the supermatrix is cero. The next step, according to Saaty methodology, is to construct the weighted supermatrix using the component matrix to weight the supermatrix previously assembled. To calculate the weighted supermatrix is a need to make the matrix stochastic. This condition is necessary for obtaining the resulting limit supermatrix. This matrix is calculated elevating the weighted supermatrix to the nth power. This procedure allows capturing the transmission of influences from all the paths of the network. For example, to obtain indirect influences through a third element, the weighted supermatrix must be powered to the square (2001, págs. 94-97).

In the model proposed in this paper, we used one ANP's additional aspect that makes part of complex decisions: the merits, as shown in Figure 5. The merits are the benefits, opportunities, costs and risks of a decision. Each of the merits has its own decision network, and it is important to notice that not all of the merits have to be present in a decision model, as in the case of this decision problem. When doing pairwise comparison of the criteria under therisks and costs merits, it is always necessary to ask what are the most expensive or risky criteria, because the costs and risks are subtracted in the formula for calculating the priorities of the alternatives(Saaty T. L., 2001, págs. 93-94). There are several formulas for calculating the synthesis of results using the software Super Decisions; for example, the additive probabilistic formula:

$$
b B_{i}+o O_{i}-c\left(1-C_{i}\right)-r\left(1-R_{i}\right) \forall i=1, \ldots, n .[i:=\text { alternatives }](3)
$$

The formulas allow obtaining the ranking of alternatives in this multi-criteria decision tool. The software Super Decision offers the possibility of making sensitivity analysis to observe how the ranking of alternatives behaves when making small changes in priorities' weights; for example, changes in the priority of the decision's merits. It is important to notice that the sensitivity analysis in the software works for all formulas except for the multiplicative formula because that one does not consider changes in the priorities of the merits.

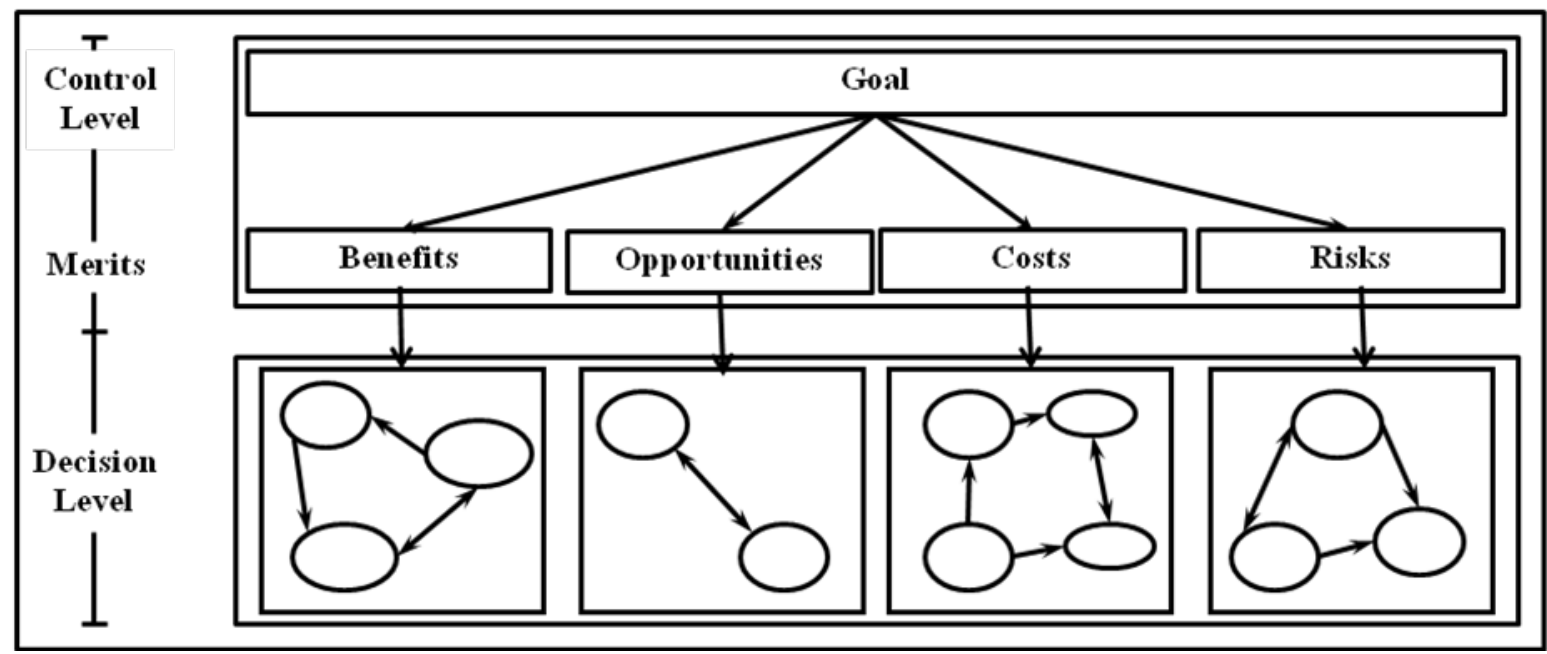

Figure 5. Proposed ANP model structure 


\section{Research methodology}

The methodology that we developed for this research is structured in the steps shown in Figure 6:

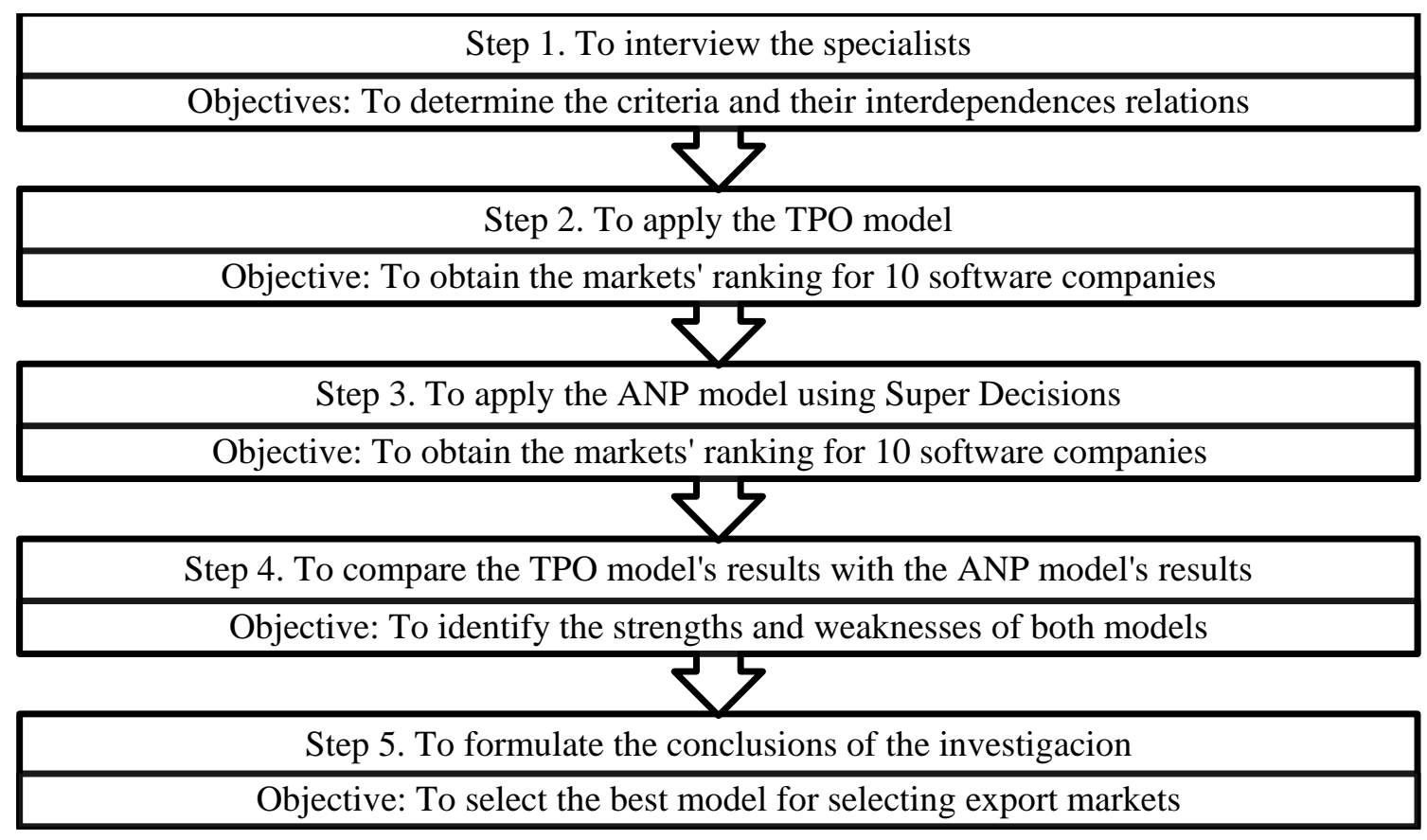

Figure 6. Research methodology

\section{Criteria's definition}

In order to determine the decision criteria that should be included in this study we used, as a reference, a model that implements ANP to support SMEs goods' producers in their internationalization process (Lesmes, 2008). From this model, we selected the components and criteria that fix to the software services sector, and then, we added other components and criteria that we considered discriminate for selecting export markets for Colombian software industry.

Table 2 shows eachof the selected criteria to evaluate the countries or the alternatives to export, and explains their relevance. The criteria were classified in seventh components by their homogeneous characteristics. The criteria mentioned next are defined because they require a detailed explanation to be understood. Country risk measures the economic risk of investing in a nation and uses a measure scale fixed by prestigious international risk qualifiers. Exports from Colombia represent the size in dollars of the software services exports from Colombia to the countries being evaluated for the last three years. Main suppliers groups 1) the countries that export software services to the market evaluated and 2) its export size in dollars, or as a percentage of the total software services' imports. Trade agreements describe the trade agreements that Colombia has with each of the evaluated countries. Taxes describe the taxes policy in the evaluated country and Intellectual property describes the intellectual property's laws that protect the software services sector in the market. Target population counts the number of companies that are potential buyers of software services in the evaluated country. Public price represents the software's price to the public in the evaluated country and Pirate price represents the price of pirate software in the evaluated country. Main competitors describes the main competitors within the evaluated country, on which description should be included the number and size of the main competitors. To measure the size of the competitors, for example, it is an option to use their profits of the last years as a measuring rule, if 
possible. Exploratory exports indicates if the company exported to the evaluated country and if it represents an opportunity to make further exports. We call this criterion exploratory exports due to the fact that the companies are not yet regular exports. Quality certificates check if the company has the quality certificates needed to export to the evaluated market and whether or not the quality certificates make the company competitive in that market. To check if the quality certificates make the company competitive, we need to compare them with the quality certificates of the main competitors in the evaluated country.

Table 2. Models' components and criteria

\begin{tabular}{|c|c|c|}
\hline Component & Criteria & Relevance \\
\hline \multirow[t]{3}{*}{ Economy } & Sector's GDP & \multirow{3}{*}{$\begin{array}{l}\text { Shows a general scenario of the IT sector } \\
\text { participation within the total GDP and the } \\
\text { purchasing power of the country. }\end{array}$} \\
\hline & Inflation & \\
\hline & Devaluation & \\
\hline Political stability & Country risk & Addresses the risk of wanting to break in a market. \\
\hline \multirow{2}{*}{$\begin{array}{l}\text { Foreign trade } \\
\text { Demand and supply }\end{array}$} & Exports toward Colombia & \multirow{2}{*}{$\begin{array}{l}\text { Represents the bilateral trade of software services } \\
\text { and the international competition to enter the } \\
\text { market. }\end{array}$} \\
\hline & Main suppliers (Countries) & \\
\hline \multirow[t]{3}{*}{ Logistic } & Calling cost per minute & \multirow{3}{*}{$\begin{array}{l}\text { These are operational costs of exporting software } \\
\text { services, or cost of providing support to the } \\
\text { software's buyers. }\end{array}$} \\
\hline & Flight duration & \\
\hline & 1 week) & \\
\hline \multirow[t]{3}{*}{ Trade policy } & Trade agreements & \multirow{3}{*}{$\begin{array}{l}\text { Provides information on software services sector's } \\
\text { barriers and benefits in the country under study. }\end{array}$} \\
\hline & Tax & \\
\hline & Intellec & \\
\hline \multirow[t]{4}{*}{ Market } & Target popula & \multirow{4}{*}{$\begin{array}{l}\text { Aims to measure the potential market's size and the } \\
\text { software services sector in the country, besides } \\
\text { quantifying aspects that affect directly the } \\
\text { profitability of exporting and the risk of } \\
\text { penetrating the market. }\end{array}$} \\
\hline & \begin{tabular}{|l|} 
Public prices \\
\end{tabular} & \\
\hline & \begin{tabular}{|l|} 
Piracy prices \\
\end{tabular} & \\
\hline & Main competitors & \\
\hline \multirow[t]{2}{*}{ Company's experience } & Exploratory exports & \multirow{2}{*}{$\begin{array}{l}\text { Checks whether or not the company has } \\
\text { disposition toward exporting and whether or not it } \\
\text { meets market requirements. }\end{array}$} \\
\hline & Quality certificates & \\
\hline
\end{tabular}

\section{Model's application}

The companies involved in this study are SMEs that belong to the software services sector in the Colombian market. Most of the companies have never export and, if they have, the percentage of the exports, as part of the sales, is small. Following next we are going to present the ANP model's applications and the TPO model for the companies involved in the study. The names of the countries are not mentioned because of confidential agreements.

\subsection{International markets selection matrix}

To apply the TPO modelit is necessary first to assign weights to the components and its criteria. To assign the weights, we organized a meeting with experts in foreign trade.In the meeting, the group deliberated about the weights they had to assign to each component and its criteria. When they reached an agreement, they allocated the weights shown in Table 3. The same weights were assigned to the components and its criteria in each of the 10 matrix models. Usually, the weights assignation is done differently; each 
company's owners, guided by a consultant, assign their own weights to the components and their criteria. But because we wanted to make results comparable, we assigned the same weights.

Table 3. International market selection matrix

\begin{tabular}{|c|c|c|}
\hline Countries & Weight & Guatemala \\
\hline \multicolumn{3}{|l|}{ External market analysis } \\
\hline 1.- Economy & 0.10 & \\
\hline Sector's GDP \$ & 0.30 & U\$82.5 Millions \\
\hline Inflation \% & 0.35 & $8.75 \%$ \\
\hline Devaluation \% & 0.35 & $0 \%$ \\
\hline 2.- Political stability & 0.13 & \\
\hline Country risk & 1.00 & $\mathrm{BB}$ \\
\hline $\begin{array}{l}\text { 3.- Foreign trade } \\
\text { Demand and supply }\end{array}$ & 0.11 & \\
\hline Exports from Colombia & 0.45 & \\
\hline 2.005 USD & & 14800 \\
\hline 2.006 USD & & 16500 \\
\hline 2.007 USD & & 17100 \\
\hline International competition analysis & 0.55 & \\
\hline Main suppliers (countries) & & Mexico, USA, Costa Rica \\
\hline \multicolumn{3}{|l|}{ Objective market selection } \\
\hline 4.- Logistic & 0.18 & \\
\hline Calling cost per minute & 0.30 & $\$ 2.400$ \\
\hline Flight duration (hours) & 0.30 & 8 \\
\hline Ticket cost (1 week) & 0.40 & US\$ 1500,00 \\
\hline 5.- Trade policy & 0.13 & \\
\hline Taxes & 0.30 & None \\
\hline Trade agreements & 0.40 & TLC-1985 \\
\hline Intellectual property & 0.30 & Intellectual property law \\
\hline \multicolumn{3}{|l|}{ Objective market analysis } \\
\hline 6.- Market & 0.22 & \\
\hline \multicolumn{3}{|l|}{ Promotion } \\
\hline Target population & 0.20 & 1000 companies. It is not a stable market. \\
\hline \multicolumn{3}{|l|}{ Competitors } \\
\hline Main competitors & 0.30 & $\begin{array}{l}\text { They usually sell packages to consumers and } \\
\text { the sales' strategy is passive }\end{array}$ \\
\hline \multicolumn{3}{|l|}{ Prices } \\
\hline Public price & 0.20 & Prices varies between $\$ 3.000$ and $\$ 2.5 \mathrm{~mm}$. \\
\hline Pirate price & 0.30 & 0.81 \\
\hline 7.- Company's experience & 0.13 & \\
\hline Exploratory exports & 0.60 & $\$ 0$ \\
\hline Quality certificates & 0.40 & 0 \\
\hline
\end{tabular}


The countries evaluated were selected in previous studies that the TPO did for the companies' in their program. Those countries are Costa Rica, Ecuador, Argentina, Chile, USA, Venezuela, Peru, Guatemala, Brazil and Mexico. Table 3 shows a part of the market selection matrix for one of those companies. In the matrix, we registered the information for one of the countries selected by the company. We do not show all the potential markets selected, so the matrix fits on the page. After completing the information for each country in the international markets selection matrix, the next step is to grade the criteria. The possible grades are five, three or one, with five as the highest rating. Each company's owner, or owners, grades the performance of each country with respect to the evaluated criterion. In this process, there is a consultant who advices the company. Later, the weight of each criterion is multiplied by its respective grade.Then, the results of the criteria that belong to a component are added to calculate the grade of the component. Finally, the weights of each component are multiplied by its respective grade and the results are added to obtain the score of the country. The alternative with the highest score is called the target country, the following one is called the alternative country, and continuing in order of importance, the remaining alternative is named the contingent country. Table 4 summarizes the ranking of the alternatives for each company. The table only includes target, alternative and contingent countries of the five countries selected by each company in order to make the table comprehensible. Costa Rica, Ecuador and Guatemala are not included in the table because none of them were selected as target, alternative or contingent country.

Table 4. Results of the TPO model

\begin{tabular}{|c|c|c|c|c|c|c|c|}
\hline Company & Argentina & Brazil & Chile & USA & Mexico & Venezuela & Peru \\
\hline \multicolumn{8}{|l|}{1} \\
\hline \multicolumn{8}{|l|}{2} \\
\hline \multicolumn{8}{|l|}{3} \\
\hline \multicolumn{8}{|l|}{4} \\
\hline \multicolumn{8}{|l|}{5} \\
\hline \multicolumn{8}{|l|}{6} \\
\hline \multicolumn{8}{|l|}{7} \\
\hline \multicolumn{8}{|l|}{8} \\
\hline \multicolumn{8}{|l|}{9} \\
\hline 10 & & & & & & & \\
\hline
\end{tabular}

\begin{tabular}{|l|l|}
\hline Target country & \\
\hline Alternative country & \\
\hline Contingent country & \\
\hline
\end{tabular}

\subsection{ANP model for selecting export markets}

To validate the network's relations of influence we brought together a panel of experts inforeign trade who evaluated each of the influence relations that we identified previously. The final network structure that we obtained is shown in Figure 7 and Figure 8.

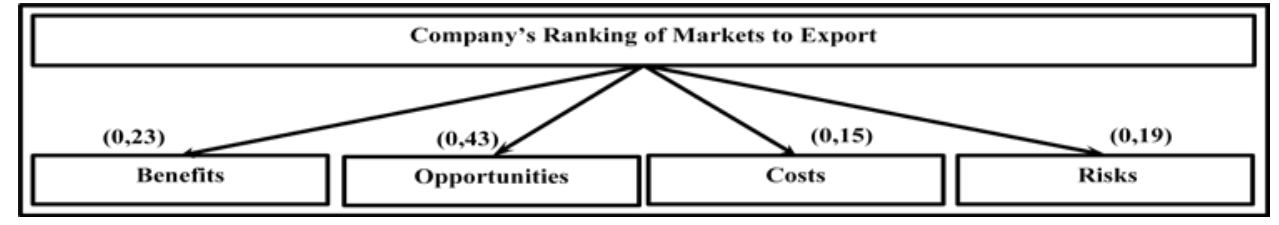

Figure 7. ANP model control level 
The judgments of the experts in foreign trade generated the merits' weights shown inFigure 7.The C.R. for this comparison was 0.017, what indicates that the comparison was done coherently. The opportunities had the highest weight, followed by the benefits, cost and risks. According to the experts' analysis, the opportunities should have a higher weight than the benefits because the evaluated markets, for most of the companies, have not been explored yet. The risks should outweigh the costs because of the same reason.

Each criterion was assigned to one of the merits' subnets to shape the four networks shown in Figure 8. The component with the alternatives is not included in the subnets to make the figure understandable. Anyway, in the four subnets the component with the alternatives influences the other components in the network and vice versa.

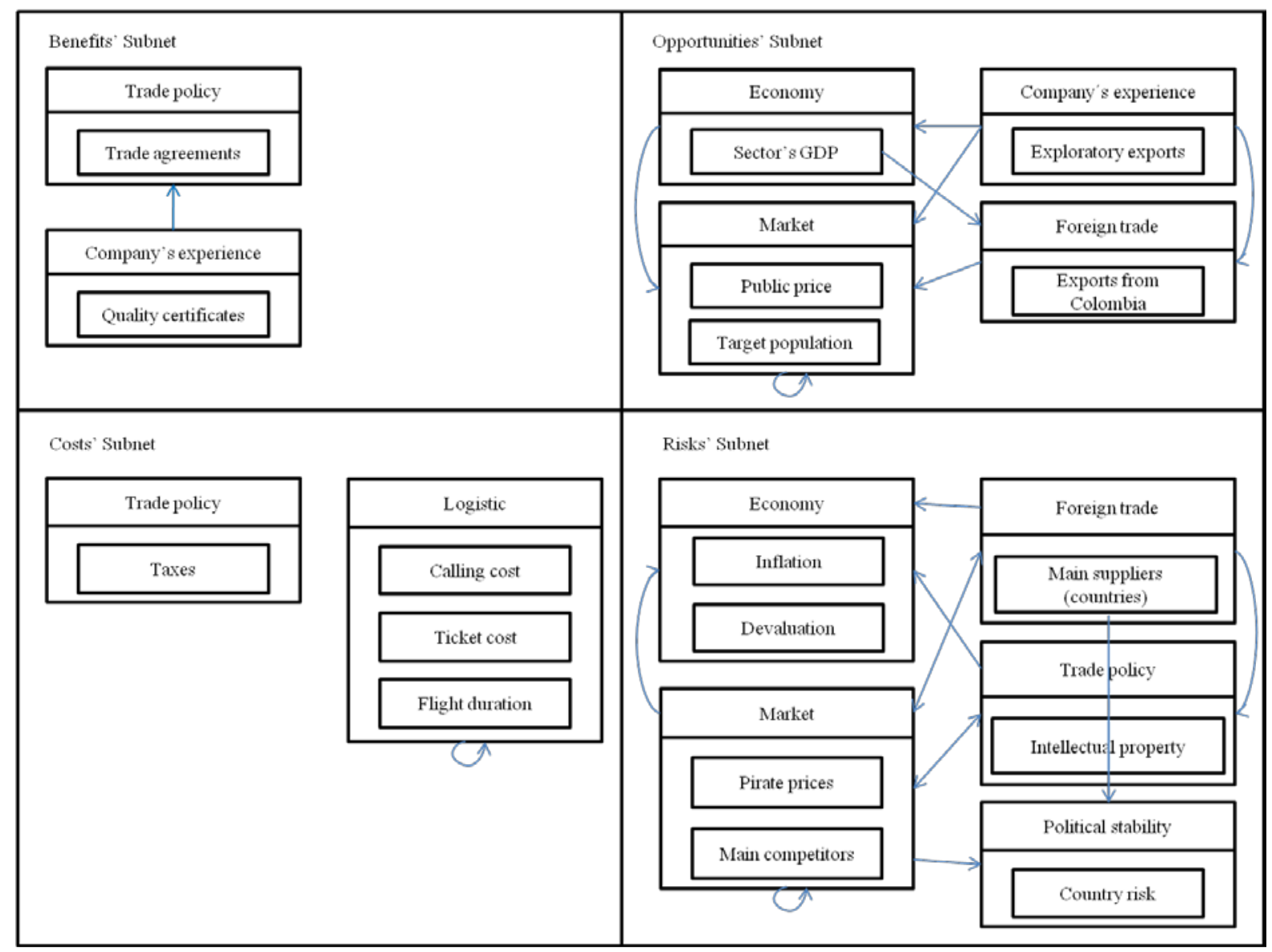

Figure 8. ANP model decision level

The dependence relations among criteria in each of the subnet are shown in Figure 8. These dependency relations appear as they do in the software Super Decisions.Therefore, the origin of the arch represents the component that is being influenced and the arrow of the arch represents the component that influences.

In the benefits' subnet trade agreements influence on quality certificates.This happens because in the trade agreements the countries are making demands on certificates of origin for products and services, what makes certificates' requirements increase for the service that the company sells. Moreover, the company's quality certificates have do not influence on the trade agreements signed by the countries. Thus, there is no arrow in the opposite direction. 
In the market component of the opportunities' subnet there is an inner-dependence loop, which shows that public price exerts an influence on target population because the service cost determines the segment of the population that can buy it. Target population, public price and exports toward Colombia influences on the sector's GDP because the valued market of the IT sector is equal to the total of consumers and investment spending, plus the exports' value, minus the imports' value. All the criteria in the subnet influences on exploratory exports because the group of experts thought that allof those criteria affect the companies' decision of making an export to some country.

In the subnet of costs there is only one relation of influence where flight duration influences on the ticket costs and vice versa. On the other hand, taxes are not influenced by the logistic costs because there is no reason for them to influence the taxes charged in the country. Thus, there is no arch directed to the logistic component.

In the risks' subnet main competitors in the market depend on the country risk and on the respect of the intellectual property. At the same time, the main competitors depend on the economic conditions, as inflation and devaluation, and on the main suppliers, or countries that provide software services to the market. The main suppliers and the intellectual property are issues that are influenced by the competence in the market. Depending on the degree of competition in a market, there can be generated protectionism policies related to imports or related to intellectual property. Additionally, the competitors' characteristics and the intellectual protection policies' quality influence the level of piracy of the software market.

The information used in the TPO model is the same used in the ANP model, but in this case the information is used to assign the judgments in the pairwise comparison matrices by the company's owner or owners with a consultant's help. It is important to notice that the C.Rs. were less than 0.1 for all the comparison matrices, which confirms that the comparisons were done conscientiously. Table 5summarizes the ranking of the alternatives for each company. The table only includes the target, the alternative and the contingent countries.

Table 5. Results of the ANP model

\begin{tabular}{|c|c|c|c|c|c|c|c|c|c|c|}
\hline Company & Argentina & Brazil & Chile & Costa Rica & Guatemala & USA & Ecuador & Mexico & Venezuela & Peru \\
\hline \multicolumn{11}{|l|}{1} \\
\hline \multicolumn{11}{|l|}{2} \\
\hline \multicolumn{11}{|l|}{3} \\
\hline \multicolumn{11}{|l|}{4} \\
\hline \multicolumn{11}{|l|}{5} \\
\hline \multicolumn{11}{|l|}{6} \\
\hline \multicolumn{11}{|l|}{7} \\
\hline \multicolumn{11}{|l|}{8} \\
\hline \multicolumn{11}{|l|}{9} \\
\hline 10 & & & & & & & & & & \\
\hline
\end{tabular}

\begin{tabular}{|l|l|}
\hline Target country & \\
\hline Alternative country & \\
\hline Contingent country & \\
\hline
\end{tabular}

We used the additive negative formula to make the synthesis of results in Super Decisions. As mentioned earlier, this software, besides providing the countries raking, also allows making sensibility analysis as shows Figure 9. This figure represents the sensitivity analysis for one of the companies in the study. As shown in Figure 7, the opportunities have a weight of 0.43. Fixing the merit's weight in that value, USA 
should be the target country and Venezuela and Guatemala, the alternative and the contingent country, respectively. This is a good tool to observe how the ranking of alternatives behaves when making small changes in priorities' weights.

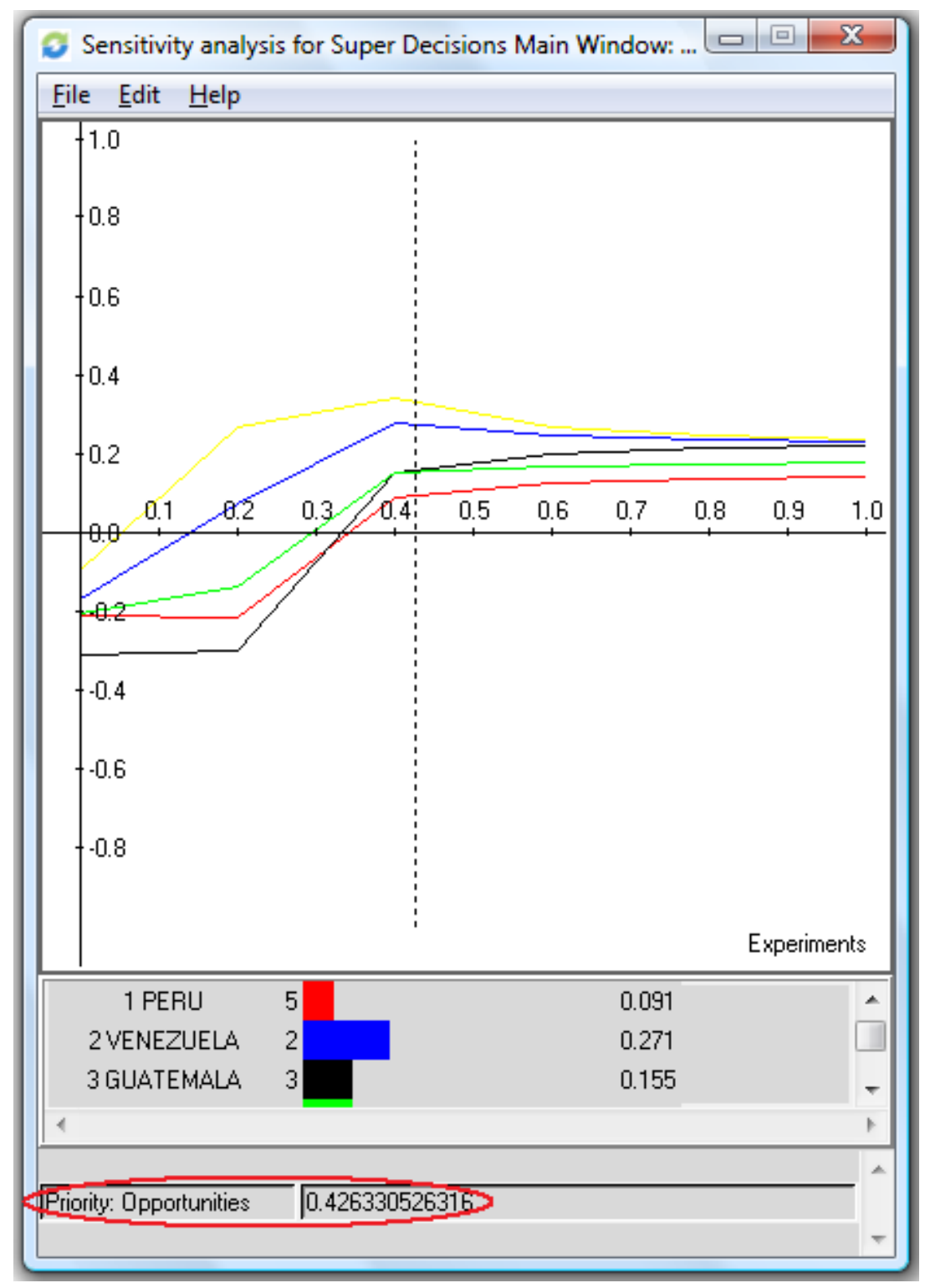

Figure 9. Super Decisions sensitivity analysis

\section{Comparison of the results obtained with the ANP model and the TPO model}

Upon comparing the market selection model of the TPO with the ANP model, we found out that the results of both models are similar in ranking the countries.

Table 6 shows the resulting target alternative and contingent countries for the companies involved in the study when applying the TPO model and the ANP model. The countries highlighted in orange are those that occupythe same ranking in both models. 
Table 6. Comparison of the results

\begin{tabular}{|l|l|l|l|l|l|l|}
\hline \multicolumn{4}{|l|}{ TPO model } & ANP model \\
\hline Company & Target & Alternative & Contingent & Target & Alternative & Contingent \\
\hline 1 & Brazil & Peru & Venezuela & Brazil & Venezuela & Ecuador \\
\hline 2 & Peru & Mexico & Chile & Chile & Mexico & Venezuela \\
\hline 3 & Peru & Chile & Venezuela & Chile & Venezuela & Argentina \\
\hline 4 & USA & Peru & Venezuela & USA & Venezuela & Costa Rica \\
\hline 5 & Brazil & Peru & USA & Brazil & USA & Mexico \\
\hline 6 & USA & Peru & Chile & Chile & USA & Venezuela \\
\hline 7 & Brazil & Peru & Venezuela & Brazil & Venezuela & Peru \\
\hline 8 & Peru & Mexico & Venezuela & Mexico & Guatemala & Venezuela \\
\hline 9 & Peru & Venezuela & Argentina & Peru & Argentina & Guatemala \\
\hline 10 & USA & Peru & Venezuela & USA & Venezuela & Guatemala \\
\hline
\end{tabular}

The results indicate that at least two countries match in the top three ranking of both models when analyzing the same company, but not necessarily in the same position. Therefore the results of both models are similar in ranking the countries. But, we concluded that the proposed model is better because it has a structured methodology to assign weights that allows evaluating the consistency of the weights allocated to the selected criteria. Besides, we also preferred it because it allows analyzing sensitivity of small changes in the priority's weights. The ANP model results generate more confidence than the TPO model results because the subjectivity is reduced. The drawback of the ANP model is that the feedback structure generates pairwise comparison matrices that are difficult to interpret, making complex the judgments assignation for the company's owners and the panel of experts. The ANP model feedback structure also generates many pairwise comparison matrices, what makes the judgments assignation process a time consuming task.

\section{Conclusions}

We chose the ANP model to select export markets for letting check the consistency of the assigned weights, for letting make sensitivity analysis and for reducing the subjectivity in the weights assignation process. It would be interesting to analyze the results that can be obtained with the AHP model as it would reduce the amount of pairwise comparison matrices by only considering the influences on elements of higher levels and simplifying the decision problem structure to a hierarchy, as Figure 3 shows. Although the AHP makes some independent assumptions among criteria, it could be a good choice for selecting the best export market as it offers the advantages of checking the consistency of the assigned weights and lets make sensitivity analysis. The complex judgments assignation would also be reduced as the lower level elements depend only on higher level elements(Saaty T. L., 2001, p. 180).

Colombia has competitive advantages in the IT sector: human resourcesare qualified; salaries are low, exception of taxes for new software products is presented, among others(Fedesoft, 2004). These conditions offer opportunities for being competitive in the international market. The ANP model offers help to company's owners in order to make informed decisions to select the best exports' markets. The best markets are those that increase the service selling opportunities and reduce the risk of failing in the export process. 


\section{REFERENCES}

Alonso, J. A., \& Donoso, V. (1994). Competitividad de la empresa exportadora Española. Madrid : ICEX. Fedesoft. (2004). Sector de servicios de software en Colombia. Bogota, Colombia.

Ferro, L. M., \& al. (2004). Pymes: gestión para la competitividad. Bogotá: Universidad de los Andes, Facultad de Administración; Casa Editorial el Tiempo, Portafolio.

Lesmes, D. (2008). Metodología para la Implementación del Proceso Analítico de Redes. Tesis de Maestría, Universidad de los Andes, Bogotá, Colombia.

Lin, Y.-H., et al. (2008). Research on Using ANP to Establish a Performance Assessment Model for Business Intelligence Systems. Experts Systems with Applictations , doi:10.1016/j.eswa.2008.03.004.

Proexport. (2006, May 23). Exportar servicios: Exporte paso a paso. Retrieved May 18, 2009, from Proexport website: http://www.proexport.com

Saaty, T. L. (2001). Decision Making with Dependence and Feedback: The Analytic Network Process (2 ${ }^{\text {nd }}$ Ed.). Pittsburgh, USA: RWS Publications, 4922 Ellsworth Avenue,Pittsburgh, PA 15213 USA.

Saaty, T. L. (2008). Relative Mesuarement and Its Generalization in Decision Making Why Pairwise Comparisons are Central in Mathematics for the Measurement of Intangible Factors The Analytic Hierarchy/Network Process. RACSAM, 102 (2), 251-318.

Saaty, T. L. (2005). Theory and Applications of the Analytic Network Process. Pittsburgh, USA: RWS Publications.

Saaty, T. L., \& Vargas, L. G. (2006). Decision Making with the Analytic Network Process Economic, Political, Social and Technological Applications with Benefits, Opportunities, Cost and Risk. United States of America: Springer. 